\title{
Note on conventions
}

The original spelling of documents has been retained, but $u / v$ and $i / j$ have been modernised and abbreviations have been silently expanded. Punctuation has been modernised where necessary and insertions to the text of a manuscript have been noted by $\wedge^{\wedge}$. Conjectured reconstructions, in the case of damaged manuscripts, are shown in square brackets. Quotations are provided in the original language and, where necessary, a translation follows in parentheses, except when quoting from translated sources. Quotations from Scripture are from the Geneva Bible (1560). Dates are Old Style, except that the year has been taken to begin on 1 January. Publications with Greek and Latin titles are given only in the latter language, but all other titles are reproduced in their original languages. The place of publication is London, unless otherwise stated.

The sisters are referred to throughout primarily by their first names to avoid confusion between natal and marital surnames. 
Gemma Allen - 9781526111951

Downloaded from manchesterhive.com at $04 / 26 / 2023$ 03:20:53PM via free access 